\title{
Imaginações rebeldes: disputas e derivações da artepensamento feminista
}

À ideia de incerteza viva (Volz, 2016) deriva a potência do risco e da instabilidade acerca de normatizações de corpos $e$ subjetividades. Podemos assumir isso como o circuito em que trafegam imaginações artísticas rebeldes, em que os corpos e suas performances dissidentes, desarticulados das convenções $e$ padrões hegemônicos, travam um embate para resistir, existir, permanecer e se (re)inventar nos variados sistemas e expressões artísticas.

Diante disso, que relações produtivas podemos estabelecer entre os pares gênero/sexualidade e arte e vice-versa, ou de que forma gênero e sexualidade, como tecnologias subjetivas, imbricam em formas artísticas e essas mesmas formas artísticas nos ajudam a repensar as relações de gênero $e$ suas interseccionalidades? Gênero, como categoria relacional, interage com outros determinantes étnico-raciais, de classe, localização e geração, o que tornam as estruturas e conjunturas nas quais interatuam essas articulações ainda mais complexas. Ao mesmo tempo, esses "atravessamentos" se dão tempo-espacialmente, constituindo processos histórico-sociais-políticos que definem as questões artísticas em tela.

Por isso, é necessário indagar: quem produz imagens $e$ narrativas e em que posição político-estética? Como e quais imagens, narrativas e enquadramentos audiovisuais enfrentaram $e$ desafiaram - em alguns casos, com a própria vida - as instituições, pessoas e práticas políticas que violentam e racializam corpos femininos, trans e queers, em terra brasilis e além-mar? Como as poéticas se imbricam com o pensamento teórico feminista em diálogo e disputa com outras abordagens? E de que maneira essa produção artística se relaciona com os movimentos socioculturais?

A partir dessas indagações-disparadoras, reunimos nesse dossiê artigos que exploram a artepensamento afro-latinohttp://dx.doi.org/10.1590/18094449202000600000 (cc) EY-No 
americana, de forma dominante. Trata-se aqui de cotejar criticamente as construções de feminilidades e masculinidades em perspectiva, do ponto de vista das indagações e profanações artístico-culturais. Os universos do teatro, da performance, das artes visuais e do cinema compõem as visualidades aqui abordadas no escopo das imaginações rebeldes.

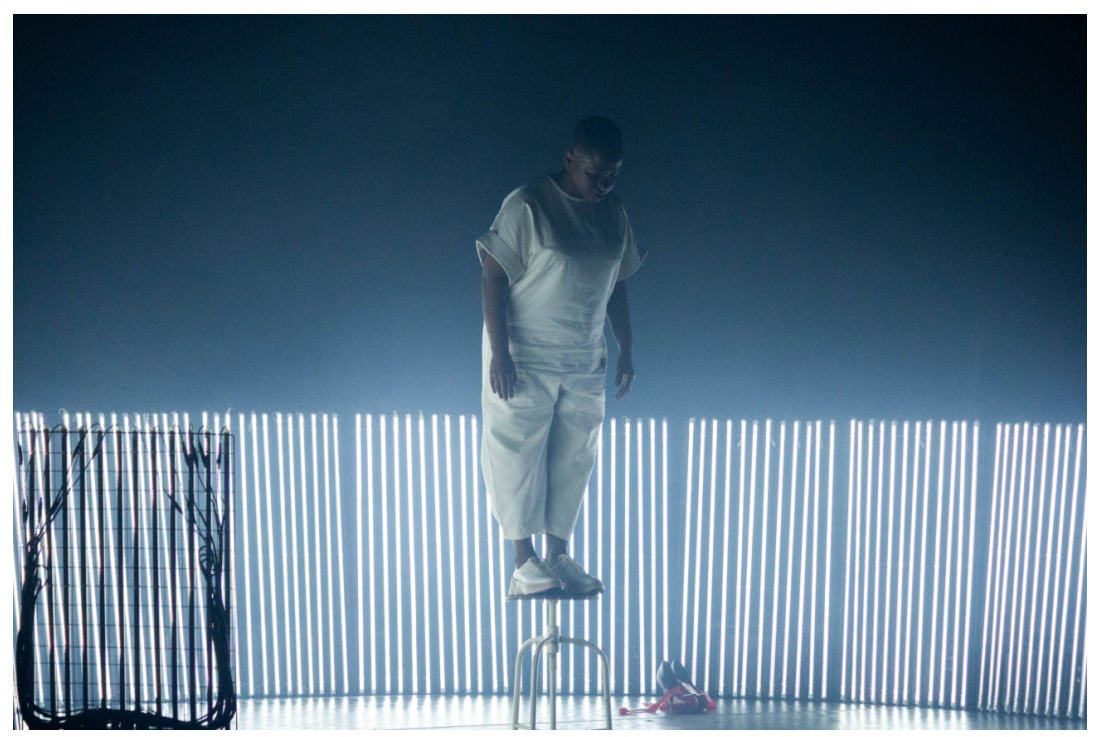

Imagem 01: Michelle Mattiuzzi, A dívida impagável (2018), estudo 1, São Paulo SP. Foto: Fernanda Vinhas.

Não se trata de celebrar tais práticas, mas investigar os processos artísticos em suas singularidades poéticas, os avanços e recuos nos arranjos entre estética e política, a intertextualidade desafiadora, as insurgências artísticas e os movimentos da sociedade, as categorias estéticas emergentes e os efeitos de sentido. Em síntese, no modo como se têm promovido confrontos e, ao mesmo tempo, constituído espaços heterotópicos de um novo que resiste às várias formas de dominação e domesticação. 
A articulação da artepensamento afro-latino-americano está sintonia com as poéticas feministas amefricanistas (Gonzales, 1988a), em que as tramas são tecidas na correlação entre estética e política, impulsionadas pela dimensão político-teórica da etnoracialização dos corpos, da questão das mulheres e o lugar do feminino no contexto da cultura afrolatinoamericana (Gonzales, 1988b). Por meios variados, os textos aqui reunidos lidam com essas disputas $e$ acionam as questões territoriais de opressão $e$ resistência, subjetividade e identidade, bem como tencionam, ao seu modo, as políticas identitárias, num movimento questionador que envolve pensar as políticas de representação (Hall, 2016), no questionamento sobre estereótipo, violência, sexismo $e$ colonização. Descolonizar a arte, portanto, implica, em libertá-la de mecanismos de controle e dominação estabelecidos historicamente, o que resultou em eurocentrismo e, com ele, a carga brutal do racismo, patriarcalismo, etnocentrismo $e$ os sexismos.

Nosso interesse, portanto, parte de uma urgência no contexto do pensamento social, artístico-filosófico, em distintas temporalidades, em recuperar, mapear e reavaliar os múltiplos $e$ disformes processos artísticos e suas respectivas proposições estéticas, em que confluem resistência e insurgência aos poderes estabelecidos, ainda, em sua maioria, ocultos, mas que historicamente foram levados a termo por mulheres negras, lésbicas, trans e indígenas contra as muitas formas de dominação, opressão e, algo imperativo no contexto artístico, as formas de colonialismo cultural.

Um processo de autopreservação e de subjetivação que se deu na e através das lutas e resistências o que não eximiu corpos $e$ vidas da precariedade e da injustiça. No meio destas forças de opressão e retenção da vida pensante e criativa, vigora o que autores de diferentes regimes disciplinares e ideológicos enunciativos tais como Michel Foucault, Judith Butler, Angela Davis, Milton Santos, Lélia Gonzales, Abdias Nascimento, Beatriz Nascimento, Beth Lobo, Gloria Anzaldúa, Stuart Hall, Rosa Luxemburgo, entre outros, motivados pela crítica à normalidade e 
normalização, bem como ao conjunto de exclusões e segregações que tais noções agregam argumentaram em relação ao que importa fazer. O pensamento destes autores nos incita a pensar $e$ buscar nas dinâmicas e exercícios artístico-culturais as práticas, códigos e gestos de resistência, as contra narrativas, as ocupações, enfim, os vários meios e modos de produção de novas estéticas e consciências que produziram e produzem (re)existências em meio $e$ ao lado daquelas práticas que reinam soltas no interior da indústria do entretenimento $e$ das artes institucionalizadas, possibilitando linhas de fuga na rotina mesma das práticas artísticas hegemônicas e estabelecidas.

Isso torna a reflexão construída aqui, no contexto do Brasil pós-2016, mimese de lutas e resistências históricas. Num movimento crescente, principalmente da última década, da emergência de mulheres, negros, LGBTQIA + e indígenas em espaços expositivos, mostras e festivais de cinema, na cena teatral etc., desaba o conjunto de interdições e censuras diretamente focadas na arte nos anos recentes de volta do autoritarismo. Desse modo, o fechamento da exposição Queermuseu (curadoria de Gaudêncio Fidelis), no Santander Cultural, em 2017, em Porto Alegre; as manifestações raivosas contra Judith Butler no SESC/POMPEIA, em 2017, em São Paulo; o cancelamento da peça $O$ evangelho segundo Jesus, rainha do céu" (escrito pela dramaturga escocesa trans Jo Clifford, com a atriz Renata Carvalho), em 2018, no Festival de Inverno de Garanhuns; os ataques à performance La Bête, por Wagner Schwartz, em 2018, no MAM, em São Paulo; as censuras explícitas a Afronte(2017), curta-metragem dirigido por Marcus Vinicius Azevedo e Bruno Victor, interdições a NEGRUM3 (2018), de Diego Paulino e Greta(2019), de Armando Praça, são pontas de visibilidade de um gigante iceberg conservador.

Para compor um campo de reflexão, as/os autoras/es convidadas/os revitalizam a importância de reflexões como as que fizeram importantes pensadoras/artistas feministas dos anos 70, por exemplo, Linda Nochlin em 1971. Seu artigo intitulado "Por que é que não houve grandes mulheres artistas?" [Why have there 
been no great women artists?] (Nochlin, 2017) parte de uma falsa (irônica) problemática, a fim de questionar todo um modo de classificar a história da arte, a partir de estéticas, estilos, cronologias e nacionalidades artísticas. Consequentemente, o cânone foi chacoalhado. No campo cinema, esse movimento de entender tanto a ausência de mulheres na produção técnica $e$ artística, quanto o modo como o feminino $e$ as mulheres foram representadas nas telas mainstream do cinema hollywoodiano, deu o tom das críticas e das novas leituras, nas relações entre filme e gênero, em autores tais como: Teresa de Lauretis, Laura Mulvey, Mary Ann Doane, E. Ann Kaplan, Alisson Butler e bell Hooks mais recentemente Patricia White, Ruby Rich, Shaw, Rosalind Galt, Margara Mílan, July Dash, Corinn Columpar. Tomando o cinema como expressão para suas indagações, Alcilene de Oliveira, Gilberto Alexandre Sobrinho, Karla Bessa, Patrícia Sequeiras Braz, Stephanie Dennison e Karla Holanda analisam filmes e realizam reflexões, em diálogo com esses e outros legados.

$\mathrm{O}$ artigo de Alcilene Oliveira, intitulado "A rebeldia do cinema de mulheres no Brasil: os desafios de Maria do Rosário Nascimento e Silva, em anos de ditadura civil-militar", volta-se para o longa-metragem de ficção Marcados para viver (direção de Maria do Rosário Nascimento e Silva, 1976). Trata-se de um filme inaugural, ao ser dirigido por uma mulher, que leva às telas uma personagem lésbica. Para abordar uma narrativa que envolve personagens que não se fixam na lógica binária masculino/feminino, a autora recorre a Alison Butler (2002) que considera o cinema de mulheres como "cinema menor". A autora aprofunda a discussão ao evocar a ideia de "cinema menor lesbiano", num contexto de forte opressão e censura, no Brasil da ditadura militar.

Os textos de Gilberto Alexandre Sobrinho e Karla Bessa situam-se no contexto da abertura política, seguido da redemocratização, momentos de forte rearticulação dos movimentos sociais, no plano social, bem como da feitura de filmes marcados pela excessiva sexualização de personagens femininas e masculinas, a partir da inflexão do cinema da Boca do 
Lixo, de São Paulo. Assim, em "Ôrí e as vozes e o olhar da diáspora: cartografia de emoções políticas", Sobrinho analisa o documentário Ôrí (direção de Raquel Gerber, 1989) que acompanha e reflete sobre a irrupção do movimento negro organizado, em dez anos de lutas, articulações e debates. Sob a narração e abordagem principal de Beatriz Nascimento, o filme articula noções caras ao seu pensamento tais como quilombo $e$ transmigração, e avança para a análise fílmica, entrelaçando esses conceitos com a ideia de montagem cartográfica, que informa sobre o ser e estar negros no Brasil e no mundo, de uma perspectiva negra e feminista. Já Karla Bessa propõe uma leitura feminista do filme Luz Del Fuego (direção David Neves, 1982) construindo uma perspectiva tridimensional na qual considera a historicidade das práticas transgressoras de Luz Del Fuego (ao mesmo tempo pessoa e personagem), a partir de distintas narrativas produzidas sobre ela e por ela. Assim, "Luz(es) Del Fuego: imagens, rebeldia e feminismos" discute a experiência radical que marcou suas lutas pela liberdade do corpo e do prazer como um modo de subjetivação rebelde. Argumenta e demonstra como, em distintas temporalidades, as tecnologias decoloniais de gênero, acionadas por Luz Del Fuego (imagens, narrativas e vida), desafiaram as hegemonias heteropatriarcais, numa lógica de expressão artístico-política pouco compreendida pelo incipiente movimento/pensamento feminista de seu próprio tempo e daquele no qual se produziu a cinebiografia (1982).

Patrícia Sequeira Braz, em "A encenação da cena: políticas feministas em Jogo de cena (2007) e The Arbor(2010)" [The staging of a scene: feminst politics in Jogo de cena (2007) and The Arbor (2010)] parte das considerações da filósofa Adriana Cavarero (2000) que diz que as práticas narrativas feministas são capazes de nutrir "narrações recíprocas" que expõem o eu aos outros, em que a auto narração potencializa uma "cena de aparência" em que agimos e falamos, e vemos os outros agindo e falando. Em seu texto, a autora examina o uso de depoimentos em primeira pessoa e suas reconstituições em Jogo de Cena (direção de Eduardo Coutinho, 2007) e The Arbor (direção de 
Clio Barnard,2010). Por meio da comparação entre os dois filmes, ela argumenta que a reencenação traz complicações ao emprego de testemunhos em primeira pessoa no cinema, produzindo duplicidade e um sentimento de estranhamento no espectador. Stephanie Dennison analisa a interação entre a cultura cinematográfica brasileira, as comunidades LGBTQIA+ e a sociedade, no começo do século XXI. A autora destaca nessa interação (e produção cinematográfica) um aumento exponencialmente no período destacado. Parte disso, como resultado do alcance aos meios de produção $e$ financiamento de grupos historicamente segregados, principalmente durante a implementação de políticas públicas para a cultura, durante o governo dos Partidos dos Trabalhadores. Com a ascensão da extrema-direita, a partir de 2018, censuras e perseguições a artistas LGBTQIA + emergiram com a intenção de silenciar essas vozes, tal como exposto anteriormente. O esforço analítico de Dennison recai, principalmente, sobre os seguintes filmes lançados nos últimos seis anos: Praia do Futuro(Karim Ainouz, 2014), Mãe só há uma(Anna Muylaert, 2016) e Bixa Travesty(Kiko Goifman e Claudia Priscilla, 2018).

Finalmente, Karla Holanda, no presente dossiê, recupera $e$ estuda o artigo citado de Nochlin (2017) e compartilha o artigo intitulado "Por que não existiram grandes cineastas mulheres no Brasil?", adaptando o questionamento para o contexto brasileiro, em que também articula respostas e perguntas contundentes sobre a questão que ela mesma (re)produz.

É nosso interesse refletir sobre os efeitos das fruições, fricções e deslizamentos advindos dos diferentes registros artísticos em vários e distintos suportes e estéticas, considerando-se as tensões que as noções de gênero proporcionam. Nesse sentido, as reflexões desenvolvidas por Edwin Culp e Sara Barragán del Rey, Fabiana Lopes e Alessandro José Oliveira nos âmbitos do teatro e dos domínios da performance, artes visuais e ativismo ampliam as discussões, disputas e derivações dos referenciais do feminismo.

No artigo "Vulnerabilidade e desejo. As superfícies de La casa de la fuerza (Angélica Liddell, 2009)" [Vulnerabilidad y deseo. 
Las superficies de La casa de la fuerza (Angélica Liddell, 2009)], os autores propõem analisar as estratégias apresentadas na peça teatral de Angélica Liddell, nomeada La casa de la Fuerza(2009). Partindo do contexto atual de violação dos corpos femininos na América Latina, os autores inspecionam a obra, em um trânsito que compreende desde as experiências pessoais da autora teatral, aos assassinatos de mulheres em Ciudad Juárez, no México. Esse território é compreendido como local de origem e fronteira dessa violência e Liddell forma um campo de resistência que começa nas superfícies e no superficial das anedotas, diálogos, notícias, corpos e imagens que compõem a peça.

Corpos e violência também estão no horizonte das reflexões de outros dois artigos nesse dossiê. Assim, em "Musa Michelle Mattiuzzi: perambulações radicais, gestos de terror e fugitividade em carne" [Musa Michelle Mattiuzzi: radical wanderings, gestures of terror and gugitivity in flesh], Fabiana Lopes traz a prática artística de Michelle Mattiuzzi (Imagem 01), focando em performances, ações efêmeras e textos, oportunamente em relações com outras artistas negras e negros, no Brasil. A compreensão das "perambulações radicais" da artista esgarça $e$ aprofunda a tensão criada pelo seu corpo e sua presença artística na esfera pública, o que se desdobra sobre os modos de compreensão e questionamento sobre a experiência histórica, política e estética da mulher negra no Brasil. Já Alessandro José de Oliveira, no artigo intitulado "Mujeres Creando: militantes feministas e arte de habitar o contraditório", debruça-se sobre o coletivo feminista Mujeres Creando, da Bolívia, para investigar suas atividades criativas de rua, na rua e em espaços expositivos, com o objetivo de aprofundar o olhar sobre as questões da arte da performance feminista. Em seu texto, Oliveira parte da problematização da linguagem desenvolvida por teóricas feministas, para criar e se apoiar na noção de 'habitar o contraditório', expressão-chave para pensar a presença da mulher no domínio da performance $e$ as demandas da arte contemporânea. 
Nossa prioridade, na junção dos autores, foi de ampliar a visibilidade de produções de mulheres em cores, raças e estilos diversos sem fazer da categoria mulher uma essência e uma exclusividade que a torna sujeito/objeto do conhecimento. Uma postura feminista no olhar e na construção de saberes e poéticas foi um critério a mais nas escolhas, $e$ isso tem mais relação com uma posição política (que vários corpos podem ocupar) do que a mulher em si. Neste sentido, autores e artistas homens (percebidos ou autonomeados) dissidentes da hegemonia masculina, estão presentes para darem sua contribuição à produção da multifacetada da análise dos efeitos dos movimentos e práticas teóricas feministas, enfrentando e ampliando os limites da arte, das imagens e dos imaginários que constituem parte da nossa cultura artística, performática e audiovisual.

Karla Bessa* Gilberto Alexandre Sobrinho**

\section{Referências bibliográficas}

BUTLER, Alison. Women's cinema: the contested screen. London, Wallflower press, 2002.

CAVARERO, Adriana. Relating Narratives: Storytelling and Selfhood, New York, Routledge, 2000.

GONZALES, Lélia. A categoria político-cultural de amefricanidade. Tempo Brasileiro n. 92/93, Rio de Janeiro, jan./jun. 1988a, pp.69-82.

GONZALES, Lélia. Por um feminismo afrolatinoamericano. Revista Isis Internacional, v. 9, Santiago, 1988b,pp.133-141.

HALL, Stuart. Cultura e representação. Rio de Janeiro, PUC/RIO, 2016.

*Pesquisadora do Núcleo de Estudos de Gênero Pagu, Professora dos programas de Multimeios/ Instituto de Artes e do Doutorado em Ciências Sociais, ambos da Universidade Estadual de Campinas, Campinas, SP, Brasil.

${ }^{* *}$ Professor do Departamento de Multimeios, Cinema e Comunicação, Instituto de Artes, UNICAMP, Campinas - SP, Brasil. gilsobri@unicamp.br / https://orcid.org/0000-0002-5083-384X 
NOCHLIN, Linda. Por que não existiram grandes mulheres artistas? In: PEDROSA, Adriano; MESQUITA, André (org.). Histórias da sexualidade: antologia. São Paulo, Masp, 2017,pp.16-37.

VOLZ, Jochen. Jornadas espirais: Incerteza viva. In: VOLZ, Jochen e REBOUÇAS, Júlia. 32a Bienal de São Paulo Incerteza Viva: Catálogo. São Paulo, Fundação Bienal de São Paulo, 2016. 


\section{ERRATA}

No artigo "Imaginações rebeldes: disputas e derivações da artepensamento feminista", com o DOI https://doi.org/10.1590/18094449202000600000, publicado em cadernos pagu (60), 2020:e206000, na página 9 ,

onde se lia:

"Gilberto Gil Sobrinho"

leia-se:

"Gilberto Alexandre Sobrinho" 